\title{
A study of graft uptake rate of myringoplasties in Bir Hospital
}

\author{
L.K. Yadav ${ }^{1}$, J. Pradhananga ${ }^{2}$ \\ ${ }^{1}$ Senior Consultant ENT, Head and Neck Surgery, ${ }^{2}$ Medical Officer, Department of ENT, National Academy of Medical \\ Sciences, Bir Hospital, Kathmandu, Nepal
}

\begin{abstract}
Chronic suppurative otitis media-tubotympanic type is one of the commonest ear diseases in the practice of otolaryngology. It mainly occurs in the people with poor socio-economic conditions hence, its magnitude is immense in remote areas of Nepal where poverty prevails the most and in people who do not have access to health facilities. The main features of this disease are ear discharge lasting more than three months, hearing loss, and perforation of the tympanic membrane. The aim of this study is to evaluate the graft uptake rate of patients who underwent Myringoplasties for Chronic Suppurative otitis media tubotympanic type. The total number of patients in the study was 129. Age of the patients varied from 13 to 45 years. Myringoplasties were performed on these patients. They were followed up at one week for stitch and ear pack removal, and then at four weeks to see for graft uptake. The graft uptake rate was found to be $81.4 \%$. There were no significant complications, except that few patients complained of pain at the site of incision for harvesting the graft. This study showed that myringoplasty has good success rate./7 and can be carried out safely for closure of tympanic membrane perforation in cases of chronic suppurative otitis media tubo-tympanic type.
\end{abstract}

Keywords: Chronic suppurative otitis media-tubotympanic type, graft, myringoplasty.

\section{Introduction}

The attempts to close tympanic membrane perforation dates back to the $16^{\text {th }}$ century using various materials such as pig's bladder membrane, skin, vein, etc. with little success till 1958, Heerman began using Temporalis fascia, which is the standard graft material today. ${ }^{1}$ Myringoplasty is repair or reconstruction of tympanic membrane perforation, which became popular during the 1960's with higher percentage of successful closure using Temporalis fascia graft, and is the standard

Correspondence: L.K. Yadav

E mail: lalkydv@hotmail.com

practice these days to close the tympanic membrane perforation. The main indication of myringoplasty is chronic suppurative otitis media-tubotympanic type, which is characterized by discharge lasting more than three months, hearing loss and perforation of tympanic membrane. ${ }^{2}$ The aim of the surgery is to prevent recurrent ear discharge and to improve hearing. Myringoplasties were performed in tympanic membrane perforations of various sizes and involving different quadrants which could influence the success rate. ${ }^{3}$ Surgery has been the mainstay of treatment for chronic suppurative otitis 
L.K. Yadav et al. A study of graft uptake rate of myringoplasties in Bir Hospital

media-tubotympanic type because the size of the perforation gradually increases with recurrent infection and discharge and hearing gradually deteriorates thereby. A success was defined as a dry and intact tympanic membrane at least one month after the operation. ${ }^{4}$

\section{Materials and methods}

This is a prospective study carried out in the Department of ENT, Bir Hospital, Kathmandu, from May 2008 to May 2010. The number of patient involved in this study was 129 . The patients selected for surgery underwent per meatal myringoplasties with underlay technique using temporalis fascia graft. Surgery was performed only on dry ears. The surgery was done under both general and local anesthesia. General anesthesia was used for apprehensive patients and those under 15 years of age. An Olympus operating microscope was used for surgery. The average duration of surgery was 75 minutes. All the operations were performed by the same surgeon. The patients were followed up in one week after surgery for ear pack and suture removal, and then at four weeks to see for graft uptake.

\section{Results}

The age of the patients in this study ranged from 13 to 45 years. The majority of patients were in age group 21-30 years (46\%), followed by 11 to 20 years (35\%), 31 to 40 years $(12 \%)$ and 41 to 50 years $(7 \%)$ (Table 1$)$. The male to female ratio was almost equal 1:1.26 with slight female dominance. The ratio of operated right and left ear was 1:1.15.51 cases were operated under local anesthesia and 78 under general anesthesia.
Table 1. Age and sex wise distribution

\begin{tabular}{lccc}
\hline Age group & Male & Female & Total \\
\hline $11-20$ & 24 & 21 & 45 \\
$21-30$ & 24 & 36 & 60 \\
$31-40$ & 6 & 9 & 15 \\
$41-50$ & 3 & 6 & 9 \\
\hline Total & 57 & 72 & 129 \\
\hline
\end{tabular}

On otoscopic examination four weeks after operation it was found that 105 patients had graft uptake which turns out to be $81.4 \%$.

\section{Discussion}

There is marked diversity in the reported success rate for achieving an intact tympanic membrane following myringoplasties. ${ }^{5}$ Controversies exist about factors thought to influence surgical outcomes. The graft uptake rate in this study was $81.4 \%$. Various similar studies have shown varying results regarding the success rate. Karela et $\mathrm{al}^{6}$ have found a graft uptake rate of $91.5 \%$ at three to six months. Brown et $\mathrm{al}^{4}$ found the success rate of 74 $\%$. Skotneska et $\mathrm{al}^{7}$ reported the success rate of 91.5 $\%$.

In the study by Lee et $\mathrm{al}^{3}$ the success rate for small perforation was $74.1 \%$ and for large perforation was $56.0 \%$, showing that small perforations have more favorable outcome. Similarly, Rehman et $\mathrm{al}^{8}$ reported success rate of $80.0 \%$ which compares favorably with this study. They also found the success rate for underlay technique to be $84.0 \%$ and for overlay technique $76.0 \%$. Success rate using temporalis fascia graft was $83.3 \%$ and using tragal perichondrium was $71.4 \%$.

Yadav et $\mathrm{al}^{9}$ reported a success rate of $80.0 \%$ in a study of endoscope assisted myringoplasties. 
Khtoum et al $^{10}$ in a retrospective analysis of 38 cases found the success rate to be $85.7 \%$. Makaya et al ${ }^{11}$ reported a graft uptake rate of $88.0 \%$ at three months and $84.0 \%$ at six months. Umapathy et al ${ }^{12}$ reported a success rate of $90.0 \%$. Karkanevatos et $\mathrm{al}^{13}$ reported a success rate of $83.3 \%$ which also compares favorable with this study. Biswas et al ${ }^{14}$ reported a graft uptake rate of $85 \%$. Harvinder et a ${ }^{15}$ quoted a success rate of $65 \%$ using amniotic membrane as graft, and $56.7 \%$ using temporalis fascia as graft. Shaikh et al ${ }^{16}$ reported a success rate of $81 \%$, male to female ratio of $2: 3$, and age range of 18 to 40 years, all of which compares favorably with this study.

In a study carried out in 124 patients, Raghavan et $\mathrm{al}^{17}$ reported a success rate of $97.23 \%$ in 106 new patients and $77.78 \%$ in 18 revision cases. Wasson et $\mathrm{al}^{18}$ reported a success rate of $80.8 \%$ which also compares favorably with this study. Thus, the review of previous articles on graft uptake by various authors and this study show that the graft uptake rate in most of the studies carried out in different parts of the world ranges from $55-90 \%$ and some of the studies show an uptake rate exceeding $90 \%$.

Myringoplasty employing underlay technique using temporalis fascia graft is an excellent surgical procedure to close tympanic membrane perforation with high success rate. Though the skill of surgeon is important factor for the success of the operation, there are other factors which can influence the surgical outcome. Among these are size of the perforation, surgical technique, graft material, eustachian tube function, previous myringoplasty and smoking history. ${ }^{7,17}$ Besides, respiratory infection and graft infection can also reduce success rate. In this study, one of the patients with graft failure gave history of blowing trumpet one week after the operation. Another patient who had graft failure had multiple tympanic membrane perforations suggesting tubercular infection. Some other patients who had graft failure got their dressings done in local clinic with possibility of improper aseptic technique of dressing.

Because of these reasons it is not possible to guarantee $100 \%$ success rate to any patient, though the surgical procedure has excellent success rate.

\section{Conclusion}

Chronic suppurative otitis media tubo-tympanic type is very common disease in the context of Nepal. The disease is easily diagnosable. Myringoplasty should be performed in these patients to render the ear dry and prevent further hearing loss, as the success rate of graft uptake is more than $80 \%$.

\section{References}

1. M.E. Glassock. Surgery of the Ear. $4^{\text {th }}$ edition. Philadelphia. WB Saunders 1990:334-48

2. R.P. Mills. Management of chronic suppurative otitis media. Booth JB. Scott-Brown's Otolaryngology. $6^{\text {th }}$ edition. Vol.3. Mumbai, Butterwrth-Heinemann 1997:10;1-9.

3. P. Lee, G. Kelly, R.P. Mills. Myringoplasty. Does the size of the perforation matter? Clinical otolaryngology and allied sciences. 2002;27(5):331-4. 
L.K. Yadav et al. A study of graft uptake rate of myringoplasties in Bir Hospital

4. C. Brown, Q. Yi, D.J. McCarty, et al. Success rate following myringoplasty at the Royal Victoria eye and ear hospital. Australian journal of otolaryngology. 2002;29:606-11.

5. R. Aggrawal, S.R. Saeed, K.J.M. Green, Myringoplasty. The journal of laryngology and otology. 2006;120:429-32.

6. M. Karela, S. Berry, A. Watkins, et al. Myringoplasty: surgical outcomes and hearing improvement. European achieves of Otorhinolaryngology. 2008;265:1039-42.

7. B. Skotniska, P.E. Hassmann. Myringoplasty in children - success factors. Otolaryngol Pol. 2008;62:65-70.

8. H. Rehman, N. Ullah, S. Muhammed et al. Factors influencing the success rate of myringoplasties. J. postgrad Med Inst.2007;21:117-21.

9. S.P.S. Yadav, N. Aggrawal, M. Julaha et al. Endoscope assisted myringoplasty. Singapore Med J. 2009;50:510.

10. N.A. Khtoum, M.A. Hiari. Myringoplasty in children, retrospective analysis of 35 cases. Brazilian Journal of Otorhinolaryngology. 2009;75:371-4.
11. I.K. Makaya. Myringoplasty results in a district hospital in Botswana. Trop. Doct. 2006;36:176-7.

12. N. Umapathy, P.J. Dekkar. Myringoplasty. Is it worth performing in children. Arch Otolaryngol Head and Neck Surg. 2003;129:1053-5.

13. A. Karkanevatos, S. De, V.R. Srinivasam et al. Daycare myringoplasty: five years experience. J. Laryngol Otol. 2003;117:763-5.

14. S.S. Biswas, M.A. Hossain, M.M. Alam et al. Hearing evaluation after myringoplasty. Bangladesh Journal of Otorhinolaryngology. 2010;16:334-8.

15. S. Harvinder, S. Hassan, S. Sidek, et al. Underlay myringoplasty: comparision to human amniotic membrane to temporalis fascia graft. Med J Malaysia. 2005;60:585-9.

16. A.A. Shaikh, M.A.S. Onale, S.M. Shaik, et al. Outcome of tympanoplasty type I by underlay technique. JLUMHS 2009;8:80-4.

17. U. Raghavan, D.S. Malki, N.A. Mahommed. Myringoplasty success rate in new and revision patients. J. Laryngol Otol 2000;114:174-7.

18. J.D. Wasson, C.E. Papadimilriou, H. Pau. Impact of perforation size in closure and audiological improvement. J. Larygol Otol. 2009;12:1-5. 